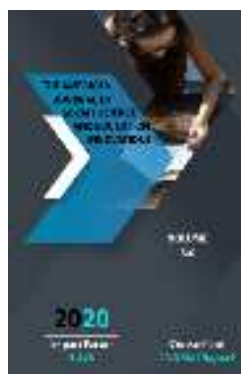

\title{
"Technology" In Secondary Schools Organization Of Science Classes
}

Shomirzayev M.Kh.

PhD, Associate Professor, Termez State University, Termez, Uzbekistan

Journal Website:

http://usajournalshub.c om/index,php/tajssei

Copyright: Original content from this work may be used under the terms of the creative commons attributes 4.0 licence.

\section{ABSTRACT}

The article deals with the organization of science lessons in secondary schools and the use of new pedagogical technologies and innovative teaching methods in its teaching.

\section{KEYWORDS}

General education, school, class, department, stage, technology science, student, competence, competent person, profession, education, thrift, entrepreneurship, technological education, market economy.

\section{INTRODUCTION}

In order to ensure the gradual transition of the country to a market economy and its full integration into the world community, a practical state policy of informatization of education has been established, the first regulatory framework with its priorities has been created. Indeed, in today's market economy, the training of creative workers, engineers and technicians in any field, including material production, is one of the most important issues. Because in the current production process, we have to solve different problems. Naturally, there are many problems in the field of engineering and technology, and without solving them, it is impossible to increase production efficiency. It employs a lot of workers, technicians and engineers bring up rationalization and ingenuity proposals aimed at improving and perfecting the production process. In accordance with these proposals, some equipment is being created, new technological processes are being established. Of course, this does not happen by itself. Those who propose such rationalization and 
invention should have a certain level of knowledge and skills in technical creativity, be aware of the methods of technical creativity. Naturally, the process of acquiring such knowledge begins at school. At school, the initial knowledge they acquire in the school workshop can be a motivation and foundation for deepening and continuing work in this area. Therefore, for every young person entering adolescence, the basics of science and technology, economics and industry it is important to impart modern knowledge, to develop them mentally and physically, to cultivate a creative attitude to work. Therefore, it is necessary to organize classes in the school workshops on the subject of "Technology" at such a level that they are not just in the state of simple copying, but also in the form in which students can work independently and creatively. 'Isin. That is, the work should be organized in such a way that it develops students' creative thinking skills, develops practical skills, and teaches students to innovate, or at least to introduce elements of innovation. Because in today's world of selfgovernment, people with creative skills such as ingenuity, initiative, entrepreneurship are needed more than ever in all areas. This requires the use of a variety of advanced forms and methods of teaching. One of such activities is the formation of students' understanding of the field of production through the use of various innovative methods in the lessons of "Technology", teaching them creativity, the formation of work skills related to artistic and technical creativity.

\section{THE MAIN PART}

The subject of "Technology" in secondary schools is of great importance in the activities of students and school life, as it is taught for a long time, from the first grade to the last grade. At the same time, the subject of "Technology" is organized in three stages at school. use, to develop labor skills in making simple things, to consciously focus on career choice.

Each of the above steps has specific tasks. In Phase 1, technology classes for grades 1-4 provide students with an introduction to the role of labor in people's lives, the simplest labor practices and tools, and their use. Basic work skills are formed by making simple things, toys, and other materials from paper, glue, fabric, yarn, plasticine, and other tools such as needles, scissors, and knives.

"Technology" lessons of the $\mathbf{2}$ nd stage are "Technology" lessons of 5-7 grades. Technology courses at this stage are organized in the areas of technology and design (metal and wood processing technology), service (basic cooking and fabric processing technology), and general areas. These are the most important forms of production and are used in almost every field. For example, in grades 5-7, students are introduced to the basics of wood, metal, fabric processing and cooking, electrical engineering and repair, which are the main links in production. in these areas they develop work skills, which in the future will be directed to the conscious choice of a profession.

Level 3 "Technology" classes are "Technology" classes in grades 8-9, which are organized in three directions, as above. An important difference between this and the second phase is that the Technology courses in this phase provide more direct advice to students on career choices and the basics of production. It teaches students about the types of professions, their characteristics, what to look for when choosing a profession. It is up to the 
students to choose which of these professions to pursue.

The main task of teaching these "Technology" subjects is to ensure the proper physical development of students, to develop their creative abilities and skills of practical work. This leads to the following goals and objectives.Texnologiya fani darslarining maqsadi: In technology classes, students are introduced to the production process, areas of production, equipment and machinery used in them, their types and uses, and are taught how to make simple products.

In the course of the subject "Technology" to further strengthen the professional orientation of students by teaching them to work with various natural and metallic and non-metallic materials on the basis of technological methods, the basics of folk crafts, home economics, electrical engineering. acquisition of knowledge, skills and abilities to apply to the profession and the formation of the ability to apply them in life.

The main purpose of teaching technology in secondary schools - to form in students the competencies to apply the knowledge, skills and abilities acquired in the course of technical and technological operations in independent practical activities, to choose a profession, to enter into social relations on the basis of national and universal values.

The main tasks of teaching "Technology" in secondary schools:- teaching materials and information about their properties, properties and technical object and technological processes;

- Knowledge of special and general labor operations in the technical object and technological processes;
- Management of technological processes, practical application of special and general labor operations;

- Formation of technical and creative thinking, intellectual abilities;

- Be able to analyze the technological process and the sequence of execution of finished products, as well as product quality;

- To draw conclusions on the implementation of labor processes for the manufacture of goods and to assess labor operations, product quality;

- The formation and development of competencies in the field of "Technology" and the basis for the implementation of conscious preparation for career choice.

In secondary schools, the subject of "Technology" is generalized in the primary grades, in grades 5-9 "Technology and design", "Service" and Generalized.

The subject "Technology" is taught in the following sections.

In grades 1-4: 1. Working with paper and cardboard.2. Working with natural and different materials. 3. Working with fabrics and fibrous materials.4. Artistic construction and technical modeling

Grades 5-7 I. In the field of technology and design: 1. Woodworking technology.2. Technology of processing polymeric materials. 3. Metalworking technology.4. Electrical work. 5. Basics of household sciences; II. In the field of service: 1. Basics of cooking.2. Fabric processing technology. 3. Basics of household sciences.

In the field of technology and design of grades 8-9: 1. Technology of folk crafts. 2. Basics of production and household sciences. 3. Basics 
of electronics.4. Creative project preparation technology.5. Career guidance; In the field of service: 1. Folk craft technology. 2. Basics of production and household. 3. Basics of electronics.4. Creative project preparation technology.5. Career guidance.

If there are enough qualified teachers, it is allowed to teach the subject "Technology" in grades V-IX in two groups in secondary schools with 25 or more students.

Each lesson is organized in accordance with safety rules and sanitary-hygienic requirements.

Students will also be provided with information on the types of professions in the field of "Technology".

In the Republic of Uzbekistan, based on the priority of continuity of education, membership, personality and interests of students, basic competencies are formed in accordance with their age characteristics.

\section{Communicative competence:}

\section{A1}

use technology terms in communication; simple description of the appearance of the product; ask and answer questions on the topic; to be polite in communication, to listen to the opinion of the interlocutor, to be able to express one's opinion.

\section{A1 +}

to behave in different situations at school, on the street, at home, to follow the culture of communication in communication; independent thinking based on the acquired knowledge; react independently to manufactured items.Axborotlar bilan ishlash kompetensiyasi:

\section{A1}

to watch and hear television and radio programs and broadcasts on the science of technology, to study the methods of work, to study the information given in magazines and newspapers.

\section{A1 +}

to use information sources (television, radio, audio-video recording, telephone) in the performance of didactic tasks, using the media to find terms related to the science of technology; adhere to media culture when opening files.O'zini o'zi rivojlantirish kompetensiyasi:

\section{A1}

study of technology; to be clean in practical work, to listen to adults, to study sciences in the circle "Skillful hands", to have such qualities as diligence, accuracy, respect; to be the right word, to explain the mistakes of peers, to help adults, children, peers, to increase their knowledge through reading and learning.

A1+

regular reading and study of various books on technology; to understand one's mistakes and shortcomings correctly, to try to correct one's mistakes, to control oneself.

\section{Socially active civic competence:}

A1

to know and follow one's student duties and responsibilities, to have a place in the classroom and in the family; helping adults, 
peers, and children, participating in school and extracurricular activities, and adhering to a culture of communication; (respect for the elder, respect for the younger), understanding of their place and responsibilities in the family; school building, classroom equipment, furniture preservation.

\section{A1+}

to know and follow the duties of childhood and school; know what rights he has in relation to his age, take care of classroom equipment, teaching aids; participation in school, family, residential activities (various events, Saturdays, etc.).

\section{National and cultural competence:}

\section{A1}

to dress modestly and always adhere to it, to be kind to friends, relatives and others, to follow the example of adults in dressing and behaving in the middle, to value one's home, school, neighborhood; to observe cleanliness, to know national holidays, to have an understanding of the rules of etiquette of the student, to know the historical monuments in the area where he lives.

\section{A1+}

know the types of art and be able to distinguish them from each other, analyze works of art, follow the internal rules of the school; to distinguish between good and bad habits, to follow the etiquette of pilgrimage, to know national values (national-cultural traditions, holidays, celebrations).

From mathematical literacy, science and technology news

\section{Competence to be aware and use:}

\section{A1}

knowing how many people are in the family, who is older, who is younger, knowing when to go to school; be able to make daily plans; to be able to draw different diagrams in daily activities, to know the holidays in our country; understand the meaning of waste and thrift and apply it in daily life.

\section{A1+}

be able to use the necessary teaching aids, raw materials in the course of the lesson, to calculate the cost per day; know the types of techniques and when they appeared.

\section{Communicative competence:}

\section{A2}

be able to express terms related to technology in foreign languages, to communicate with their friends in the language of technology; be able to ask and answer questions logically based on the topic; adherence to a culture of communication, ability to work in a team.

\section{A2+}

to defend and persuade one's position by analyzing the opinion of the interlocutor in the course of a conversation on the subject of technology; to manage their passions in various conflict situations, to react to disagreements fairly, justly and positively, and to make the necessary decisions.

\section{Competence in working with information:}

\section{A2}

use available sources of information (internet, television, radio (audio-video recording), 
telephone, computer, e-mail); to follow the media culture in the search, sorting, processing, transmission, storage, security and use of information necessary for the study of technology in the media;

\section{A2+}

be able to work with documents encountered in daily activities, search, study, analyze, apply sources related to technological maps and schemes.

\section{Self-development competence:}

\section{A2}

in-depth study of the science of technology in the field, the introduction of their inventions in the field in accordance with today's requirements, the ability to approach the design profession in the manufacture of each product, as a person constantly - selfdevelopment; take responsibility for working in groups, be a leader, be able to make the right decisions in different problem situations; proper exercise of constitutional rights and duties; striving for physical, spiritual, mental and intellectual perfection.

\section{A2+}

to be able to demonstrate their abilities as an individual according to their interests, to have human qualities such as conscious choice of profession, honesty, integrity.

\section{Socially active civic competence:}

\section{A2}

knowledge of healthy beliefs and worldviews; not to be indifferent to what is happening in society, to express their attitude; understanding the nature of professions and making conscious choices.

A2+

Knowledge and observance of human, civil rights, freedoms and duties.

\section{National and cultural competence:}

A2

to study their historical, spiritual and cultural heritage, to preserve it, and to respect its traditions and ceremonies in the field of folk crafts.

A2+

their historical, spiritual in the direction of folk crafts and the study, preservation, and respect of cultural heritage and traditions; to know and respect values of universal importance.

From mathematical literacy, science and technology news

\section{Competence to be aware and use:}

A2

to be aware of and be able to use scientific and technical innovations that facilitate human labor, increase labor productivity and lead to favorable conditions.

A2+

to be able to tell about the role of our country in the world community and the period of its historical formation, to know the growth rates in all areas of our country during the years of independence; be able to read and use a variety of formulas, models, and diagrams in daily activities. 
- The formation and development of general labor skills in students, the formation and development of general labor culture, the qualities that are the basis for the choice of professions according to their interests, abilities, professional inclinations;

- Mental and physical actions performed by students, aimed at the creation of material goods, are a process of labor, the acquisition of knowledge about the tools, means and processes of labor, as well as production labor and skills in a particular field, conscious choice of profession and aimed at developing personal qualities and thinking that allow them to engage in labor activities for the benefit of society and the individual. Hence the science of technology

The DTS states: - to teach the basics of the content of various industries, to use measuring instruments, data sources, to perform labor practices, to draw conclusions by comparing the results of labor with the established requirements;

- To provide knowledge about the techniques and technologies used in various sectors of the economy, to enable them to get acquainted with various areas of human activity through practical work;

- Study the basics of working with mechanized and electrified vehicles, technological knowledge and skills, labor legislation, safety regulations, sanitary and hygienic requirements;

- To teach students the means of growing high-quality, competitive consumer goods, labor products and delivery of products to consumers in accordance with the requirements of the laws of a market economy, the formation and development of managerial, sponsorship, business qualities;

- To instill in students a desire for knowledge and love for work, respect for the working man, to educate them in the spirit of community, devotion to the Fatherland;

- Restoration and development of the national spirit, way of life, traditions of the people through the teaching of folk crafts. To teach national values, historical monuments, rich heritage of national masters, to strengthen skills of their use in practice;

- Ensuring the study of new production and application of information technology, computer engineering, new machinery and equipment at the level of modern requirements and in accordance with world experience;

- To teach the use of tools, equipment, devices used in the professional activities of various specialties in the upper grades.

It is clear that the science of technology plays an important role in educating schoolchildren. Therefore, it is necessary to pay special attention to the organization and conduct of technology classes. In particular, we believe that the use of new pedagogical technologies will give good results. To achieve this goal, the following educational and developmental tasks will be required:

The educational task is to teach students the scientific basis of labor processes, professions, general technology, techniques and production, to guide them in choosing a profession, to acquaint them with at least three professions in order to form them into competent individuals. training and preparation for education in professional colleges. 
The educational task is to develop high moral qualities, creative approach, diligence, patriotism, thrift and entrepreneurship in the attitude to work and profession, as well as a sense of sophistication in the process of formation of labor skills in students.

The developmental task is to provide students with mental, physical, moral, artistic and aesthetic education and training in the process of technological education, to apply the knowledge, skills and abilities acquired in the lessons of labor education in other disciplines. to help them grow into well-rounded individuals through pre-professional training.

The content of the subject "Technology" is conventionally divided into three parts: labor training, vocational training and pre-vocational special training. These parts are embedded in each lesson and lesson, and their analysis by teachers and methodologists from a scientific and methodological point of view ensures that the technology lessons are goal-oriented and successful. increase.

Areas of "Technology" are selected according to the areas and professions that are common in the enterprises, organizations, farms and vocational colleges around the school. Schools in areas with large industrial production should have the opportunity to direct students to modern professions in the field of "Technology".

In order to implement the lessons of "Technology" it is necessary to solve the following organizational and methodological tasks: [13, P.27].

Organizational tasks. Establishment of a classroom for theoretical lessons on "Technology" and a workshop for practical lessons and creation of safe and comfortable working conditions in them. To provide students with the necessary raw materials, materials, equipment for the lessons, as well as to organize the process of practical work with devices, mechanisms and machines. Ensuring full compliance with the requirements of sanitary and occupational safety regulations and regular monitoring.

Establish regular contact with businesses, communities, organizations, and institutions to help students become more familiar with the work processes and careers of different professions.

Official documents: normative planning documents, safety in the workshop, sanitary and hygienic requirements and rules of first aid [13, P.139].

Methodological tasks. Develop a half-year or one-year work plan, with a selection of occupations that can be intimately introduced to students based on the classification of occupations, taking into account local conditions, needs, and opportunities. Carrying out specific occupations and career choices for boys and girls in the subject of "Technology". Modern pedagogical and information technologies, new didactic materials, extensive use of tools, ensuring the unity of education and training. To develop students' basic work skills and diligence in various professions. Taking into account the age, personal psychological and physiological qualities of students in the intellectual and moral development of students in the course of technology lessons. Regularly monitor students' knowledge, skills and abilities.

The sequence of organizing and conducting classes in the areas of technology in the program is decided by the teacher, taking into account local conditions and opportunities. 
In conclusion, it can be said that the tasks of the science of "Technology" are in a complex dialectical relationship with the content. To understand this, it must be borne in mind that the tasks of the science of "Technology" are set and solved at different levels.

\section{CONCLUSIONS}

Based on the above considerations, the following can be concluded:

1. There is a great opportunity in the lessons of "Technology" to acquaint students with the main links, areas of production, to prepare them for independent living and to guide them to choose different professions. Therefore, it is the professional duty of every teacher of "Technology" to achieve a thorough organizational, methodological, scientific, technical, ideological and political lessons of "Technology".

2. The formation of students' cognitive activity, the formation of positive and creative work skills in the lessons of "Technology" is a complex process carried out through the most important pedagogical, psychological, physiological and technical-technological factors. It is important to remember that there is no substitute for a teacher. Therefore, first of all, the teacher must constantly improve their professional skills, scientific and methodological level.

3. In order to educate students and increase their activity in the process of "Technology" in secondary schools, it is simple, that is, innovative, along with traditional forms and methods of teaching. the use of pedagogical technologies also gives good results. In order to increase the efficiency of this work, it is necessary to carefully plan the stages of implementation of this work.

\section{REFERENCES}

1. Babanskiy Yu.K. Modern general education teaching methods. $T$.: Teacher, 1990. - $232 \mathrm{p}$.

2. Yuldashev J.G., Usmonov S.A. Fundamentals of pedagogical technology. T .: Teacher, 2004. - 236 p.

3. Karimov I. The use of interactive teaching methods in the lessons of labor education: Textbook. T., RTM, 2009. - 24 p.

4. Karimov I. Teaching technologies in labor education: Textbook. T., TDPU, 2013. - 228 p.

5. Karimov I. Coordinated technologies for the organization of creative activity of students in labor education: Monograph, methodological direction. $\mathrm{T}$.: Sparks of Literature, 2015. - 172 p.

6. Muslimov N.A. and b. Occupational Education Teaching Methods and Career Guidance: A Textbook. T., 2014.

7. Ochilov M. New pedagogical technologies. Opposite: Nasaf, 2000.

8. Calendar-themed plan on the subject of technology, pp. 1-9. T .: RTM, 2018.

9. Tolipov OK, Usmonbaeva M. Application bases of pedagogical technologies: textbook. T .: Fan, 2006.

10. Sharipov Sh.S. and b. Labor Education: Textbook, 5 p.m. T .: Sharq, 2015.

11. Sharipov Sh.S. and b. Technology: Textbook, 6 p.m. T .: Sharq, 2017.

12. Sharipov Sh.S. and b. Technology: Textbook, 7 p. T .: Sharq, 2017.

13. Shomirzaev M.Kh., Karimov II Inno-vast pedagogical technologies of teaching technology. Textbook. T .: “University”, 2020, 27, $139 \mathrm{p}$. 
14. Shomirzayev M.X. Ways to increase the effectiveness of teaching technology. Methodological manual. T .: 2019, 56 p.

15. Kakhhorov S.K., Zhuraev A.R. Method of application of virtual stands in teaching subjects of electrical engineering, radio engineering and electronics// LXII International correspondence scientific and practical conference «International scientific review of the problems and prospects of modern science and education» (Boston. USA. September 2223). 2019. - P. 44-47.

16. Zhuraev A.R. Research and methodology background to the optimization of labour and professional training curriculum in general secondary education // International scientific journal. № 7 (35) / Russia Volgograd. International scientific journal. № 7 (35) / Russia Volgograd. Impact factor of the journal «Science and world» 0.325 (Global Impact Factor 2013, Australia) 2016. - P. 70-71.

17. Zhuraev A.R.Using Electronic Teaching Materials for Training Future Teachers // "Eastern European Scientific Journal”. Auris Kommunikations - und Verlagsgesellschaft $\mathrm{mbH}$. Journal ausbage 1 - 2019. Germany. Pg, 432-435.

18. Zhuraev A.R. Methods of applying virtual laboratories in teaching hydraulics and heat technology // "European Journal of Research and Reflection in Educational Sciences”. -Great Britain. 2019. №7 (7). - P. 35-40.

19. A.R.Zhuraev, Kh.Bmukhamedova, F.N.Mirzhamolova G.A.Mirzhamolova. Scientifikmethodologigal basis for coordination of labor education curriculum. "The Way of science" International scientific journal. № 6 (40) / 2017, Russia Volgograd. Pg, 70-72.

20. Zhuraev A.R., Yuldashev Kh.D. Aplication methodology for online laboratories at teaching metal-processing methods // International scientific journal. № 6 (40) / Russia Volgograd.Impact factor of the journal «The Way of Science» - 0.543 (Global Impact Factor, Australia) Impact factor of the journal «The Way of Science» - 0.350 (Open Academic Journals Index, Russia) 2017.- P. 67-69.

21. Zhuraev A.R. Types of education and importance of ensuring the coherence of education content in terms of subject. "Science and world" International scientific journal. № 7 (35) / 2016, Russia Volgograd. Pg, 67-69.

22. Zhuraev A.R. The choice of the optimized content of labor education and the methodology for teaching it (5A112101 Methodology for labor training). Tashkent 2014 from 107.

23. Rasuljanovna, Ismatullayeva Nargiza. The concept of "lacuna" in translation studies. Asian Journal of Multidimensional Research (AJMR), 9, 4, 123-129, 2020.

24. Zhuraev A.R., Aslonova M.S., Bakhranova U.I. Methodology of using electronic textbooks in teaching the direction "Technology and design" of the subject of technology // "Problems of pedagogy" scientific and methodological journal № 3 (35) / Russia, Moscow. 2018 .-- S. 23 - 25.

25. Farfieva K. A. Social Media as a factor in formation of scientific thinking in youth. European Journal of Research and Reflection in Educational Sciences. Vol. 8 No. 10, 2020. - Pp. 52-56. 
